\title{
The use of the 'Kono perpendicular applied field method' in microwave palaeointensity experiments
}

\author{
Mimi J. Hill and John Shaw \\ Geomagnetism Laboratory, University of Liverpool, Liverpool L69 7ZE, U.K. \\ (Received October 6, 2006; Revised March 7, 2007; Accepted March 14, 2007; Online published July 20, 2007)
}

\begin{abstract}
For a complete understanding of the Earth's magnetic field behaviour it is necessary to have information regarding variations in its strength as well as directional changes. In order to reduce the lengthy experimental time for palaeointensity experiments and potentially reduce the possibility of mineralogical alteration Kono suggested a single heating perpendicular applied field variant of the most widely used double heating palaeointensity method (the Thellier method). Whilst in the past this method has not been generally used, due mainly to technical difficulties, it is ideal for use with the microwave palaeointensity technique. Reproducing the amount of microwave energy absorbed by a sample is not as simple as reproducing the temperature in an oven so a palaeointensity method that only has a single application of microwave power at each step is an advantage. One of the uncertainties in the original Kono method lies in getting the natural remanent magnetisation of the sample aligned perpendicular to the applied laboratory field. With the microwave systems this uncertainty has been essentially removed. The microwave variant of the perpendicular applied field method which incorporates checks for perpendicularity, as well as the usual checks for alteration and non ideal behaviour is routinely applied as it is quick and easy to use, avoids any potential power reproducibility issues and provides a comparison with results obtained through other methods.
\end{abstract}

Key words: Palaeointensity, microwave method.

\section{Introduction}

There are far more data describing the directional changes of the Earth's magnetic field than information regarding its strength. Obtaining a complete knowledge of geomagnetic field strength variation throughout Earth history is more difficult due to the complex experimental procedures and the finding of suitable material to study. The strength of the natural remanent magnetisation (NRM) held by a sample is dependant on the magnetic mineralogy, grain size, and concentration of magnetic minerals as well as the ambient field strength at the time of remanence acquisition. In order to determine absolutely the past field strength the natural process of remanence acquisition must be recreated in the laboratory. This is possible if the NRM is a thermal remanent magnetisation (TRM) gained as the magnetic minerals cooled below their blocking temperatures. A laboratory induced TRM acquired in a magnetic field of known strength can be compared to the NRM and since the strength of magnetisation is directly proportional to the strength of the applied field (Nagata, 1943) the ancient field strength can be deduced. This method relies on the fact that no mineralogical changes occur that alter the remanence acquisition capacity of the magnetic minerals and that there has been no later secondary acquisition of magnetisation. Unfortunately, natural rocks are prone to alteration on heating and often contain a secondary component of magnetisation.

Copyright (c) The Society of Geomagnetism and Earth, Planetary and Space Sciences (SGEPSS); The Seismological Society of Japan; The Volcanological Society of Japan; The Geodetic Society of Japan; The Japanese Society for Planetary Sciences; TERRAPUB.
Thus, rather than carrying out a single heating and cooling to above the Curie temperature of the sample to induce a full TRM, Thellier and Thellier (1959) introduced carrying out paired heating and coolings, step wise, to incrementally higher temperatures. In this way the partial TRM (pTRM) gained and the pNRM lost for each temperature step can be evaluated from room temperature up to the Curie temperature. It is therefore possible to select only those data from temperature steps before alteration has occurred and after the secondary remanence has been removed. The method relies on the so called Thellier laws of reciprocity, independence and additivity which hold for single domain non interacting grains. The vast majority of absolute palaeointensity methods are based on the method of Thellier and Thellier (1959) and include checks for alteration and non ideal behaviour (as the majority of rocks do not contain single domain non-interacting grains) (see Valet, 2003 for a review of palaeointensity methodology). In this paper the variant of Kono (Kono, 1974; Kono and Ueno, 1977) is described and the applications of this method to microwave palaeointensity methodology discussed.

\section{The Original 'Kono Perpendicular Applied Field Method'}

Reducing the lengthy experimental time and limiting alteration during the experiment were the main motivations for the development of a new variant of the Thellier palaeointensity method by Kono (Kono, 1974; Kono and Ueno, 1977). Kono noted that instead of heating twice to a particular temperature (in order to determine the NRM re- 
maining and the TRM gained) a single heating is sufficient as long the direction of the field is known and it is not parallel to the NRM direction. Inducing the TRM perpendicular to the NRM was chosen in order to minimise errors. Thus, Kono proposed a new perpendicular applied field variant of the Thellier palaeointensity method that involved only a single heating step being performed at each temperature step with the TRM induced perpendicular to the direction of the NRM. Vector analysis is used to evaluate the separate NRM and TRM components from the measured combined total vector of magnetisation (RM). This method reduces the amount of heating the sample experiences and consequently the experimental time (heating can be reduced by up to half depending on the number of remanence checks carried out). Additionally, less heating could result in a reduction in experimentally induced alteration.

In order to induce a TRM perpendicular to the NRM Kono and Ueno (1977) carefully aligned their samples so that the NRM for each sample lay in a plane perpendicular to the axis of a specially built electric furnace. To ensure that any secondary viscous components of magnetisation were removed all samples were first demagnetised to $100^{\circ} \mathrm{C}$ and the residual magnetisation taken as the 'NRM' or rather the characteristic remanence (ChRM). Results were presented from a historic Hawaiian lava flow and Oligocene rhyolites and welded tuffs from the San Juan volcanic field, Colorado, USA using both the conventional double heating Thellier technique and the modified method. Their investigation indicated that the two methods gave comparable results. No evidence was given for a reduction in alteration when using the single heating perpendicular applied field method indicating that for these samples the alteration predominantly occurred during the first heating step.

As shown by Kono and Tanaka (1984) the single heating perpendicular applied field method has higher errors associated with it compared to double heating methods but the authors conclude that the reduction in heating and additionally the possibility for reduction in alteration during the experiment compensates for this drawback. We have found within the literature two published studies that used the modified method in its original form; Downey and Tarling (1984) when investigating the timing of volcanic eruptions on Santorini and fired destruction levels of the late Minoan civilisation and secondly a study of Scottish Devonian volcanic rocks by Kono (1979). The method has however not been routinely used for determining palaeointensity. The main reasons for this are 1) the technical difficulties in ensuring that the sample experiences an applied field that is indeed perpendicular to the ChRM and 2) the method is only applicable if the ChRM is well known and stable. Error in the alignment of samples in the oven induces significant errors in the pNRM components if the ratio of laboratory to the ancient field is considerably less than unity. In the most commonly used double heating method (Coe, 1967) the pNRM is measured directly. The Kono method is also only applicable if the samples do not exhibit anisotropy of TRM as in anisotropic samples the induced TRM will not necessarily be in the direction of the applied field. This is not usually a problem for lava but can be with archaeological material (e.g. Rogers et al., 1979). There is however renewed interest in the method, or modifications of it, as applying the field and inducing the TRM perpendicular to the NRM has been shown to have advantages for minimising the non-ideal behaviour of multi-domain grains (Xu and Dunlop, 2004; Biggin, 2006).

\section{Microwave Palaeointensity Systems}

Minimising alteration during palaeointensity experiments was the motivation for the development of the microwave palaeointensity technique. In this method, high frequency microwaves are used to directly excite the magnetic spin system within the magnetic grains in order to de (re) magnetise, as opposed to the usual method of heating the whole bulk sample in order to excite the magnetic spin system via the phonon system (Walton et al., 1993, 1996). As the bulk sample experiences far less heating (e.g. Hill and Shaw, 2000) alteration during the experiment is minimised. It has been demonstrated that a microwave induced TRM $\left(\mathrm{T}_{\mathrm{M}} \mathrm{RM}\right)$ is equivalent to a conventional one (Hill et $a l ., 2002 \mathrm{a}$ ) and the method has been successfully used with a whole range of material from archaeological (e.g. Shaw et al., 1996; Casas et al., 2005) to geological (e.g. Hill et al., 2002b; Thomas et al., 2004; Halls et al., 2004; Gratton et al., 2005b; Hill et al., 2005).

In any double heating palaeointensity method (whether by microwaves or conventional heat), the amount of energy given to the magnetic minerals needs to be accurately reproducible. Unlike thermal demagnetisers, where it is possible to reproduce temperature to $1^{\circ} \mathrm{C}$, it is not so simple to reproduce microwave energy within the sample. With microwave excitation it is not a matter of being able to reproduce the applied power accurately as this is not the same as the power absorbed by the sample. The amount of power that the sample absorbs is dependent on the resonant microwave cavity characteristics and these are not constant since the cavity is part of the microwave circuit and acts as an amplifier. The cavity characteristics are highly sensitive to such factors as sample position, humidity and temperature. The need for accurate power absorption reproducibility is heightened for samples that exhibit a narrow blocking spectrum and thus demagnetise within a small power range. The first version of the microwave system which operated at a frequency of 8.2 GHz (see e.g. Hill and Shaw, 1999 for a description) had to be manually kept in tune (by adjusting the microwave frequency) during microwave application. An exposure time of 10-15 seconds was found to be suitable in order to do this. To limit absorbed power reproducibility as a possible source of error it is desirable to have just one microwave application at each power level as in the perpendicular applied field method of Kono. Thus the Kono and Ueno method was adapted for use with microwave palaeointensity experiments using samples with low or negligible anisotropy such as lava (Hill and Shaw, 1999).

The signal generator which forms part of the current microwave system (operating at $14 \mathrm{GHz}$; see e.g. Bohnel et al., 2003 for a description) is under remote computer control so the system can be automatically kept in resonance. As a result the absorbed power reproducibility has improved and a shorter microwave exposure time of five seconds is routinely used. In addition, the applied (forward) and reflected 
power are now monitored during the microwave application and the difference calculated (the so called 'power integral') to give an indication of reproducibility. Some of the power may be absorbed by something other than the sample (e.g. dirt in the cavity) however it is expected that the power integral will be similar for the same applied power and power absorption by the sample. As a general rule it has been found that the power integral for a particular applied power is consistent to within $5 \%$, and if it is not then a difference in remanence acquisition/demagnetisation is seen. Thus the possibility of including checks and using double 'heating' microwave power methods became possible (e.g. Hill et al., 2005; Gratton et al., 2005a). The perpendicular applied field method is however still used (with $\mathrm{pT}_{\mathrm{M}} \mathrm{RM}$ and $\mathrm{pT}_{\mathrm{M}} \mathrm{RM}$ tail checks) as it eliminates one potential source of error in the microwave palaeointensity experiment plus it is quicker.

\section{The Microwave 'Kono Perpendicular Applied Field Method'}

The palaeointensity experimental procedure differs from that of Kono and Ueno (1977) in which the applied laboratory field $\left(\mathrm{F}_{\text {lab }}\right)$ has constant direction and the samples themselves are oriented so that their NRM direction is perpendicular to the laboratory field. In the microwave variant the samples remain fixed and the direction of the laboratory field is changed. The current $14 \mathrm{GHz}$ microwave system has two Helmholtz field coils which can produce a field in the $\mathrm{Z}$ and $\mathrm{Y}$ directions respectively. It is therefore possible to apply a field in any direction within the $\mathrm{Z} Y$ plane with any magnitude up to $100 \mu \mathrm{T}$. Thus a key difficulty with the original perpendicular method is overcome.

Sister samples are usually first fully microwave demagnetised to check their directional stability and demagnetisation behaviour. For the palaeointensity experiment the first step is to remove all viscous and secondary components by microwave demagnetisation until only the stable ChRM remains. The direction of $F_{\text {lab }}$ is then calculated and applied to the microwave cavity. The field remains on unless the user specifies for it to be switched off, for instance when carrying out a $\mathrm{pT}_{\mathrm{M}} \mathrm{RM}$ tail check (Riisager and Riisager, 2001) (which also acts as a check on remanence stability). In the microwave palaeointensity technique, the whole palaeointensity experiment is carried out one sample at a time as opposed to the batch heatings in conventional experiments. This allows analysis of the results to be carried out parallel to the experiments and if it is found, for example, that the ChRM is not stable then that particular experiment can be abandoned immediately. It also enables the microwave power steps to be chosen to suit the unblocking spectrum of each individual sample.

Two methods are used to calculate the NRM and $\mathrm{T}_{\mathrm{M}} \mathrm{RM}$ components with consistency between the results providing a quality check (Fig. 1). The first method assumes that the total vector of magnetisation (RM) is in the plane defined by the direction of $F_{\text {lab }}$ and the ChRM. The NRM is then the scalar product of RM and the ChRM direction unit vector, and TRM the scalar product of RM and the $F_{\text {lab }}$ direction unit vector.

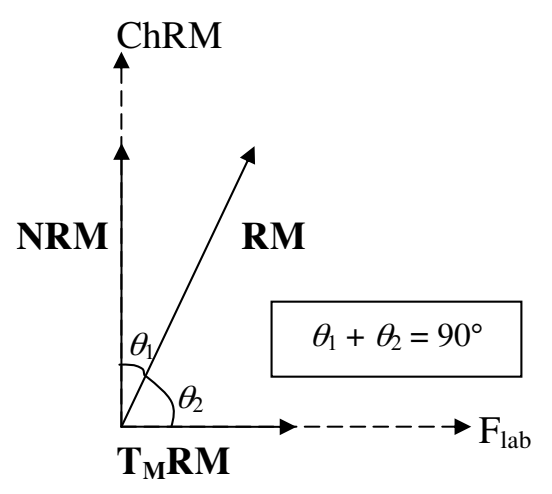

Fig. 1. Illustration depicting the NRM and $\mathbf{T}_{\mathbf{M}} \mathbf{R M}$ components and the total vector of magnetisation $\mathrm{RM}$ along with the direction of $\mathrm{F}_{\text {lab }}$ and the direction of the ChRM in the microwave perpendicular applied field palaeointensity method.

Method 1 .

$$
\begin{aligned}
& \mathrm{NRM}=\mathbf{R M} \cdot \boldsymbol{C h} \boldsymbol{R} \boldsymbol{M} \\
& \mathrm{T}_{\mathrm{M}} \mathrm{RM}=\mathbf{R M} \cdot \mathbf{F}_{\mathrm{lab}} .
\end{aligned}
$$

Where normal type indicates a scalar (magnitude), bold type indicates a vector and italics the directional unit vector.

The second method evaluates the angle between RM and the $\operatorname{ChRM}\left(\theta_{1}\right)$ and $\mathrm{F}_{\text {lab }}\left(\theta_{2}\right)$ directions in order to determine the NRM and TRM components (Fig. 1).

Method 2

$$
\begin{aligned}
& \mathrm{NRM}=\mathrm{RM} \frac{\sin \theta_{2}}{\sin \phi} \\
& \mathrm{T}_{\mathrm{M}} \mathrm{RM}=\mathrm{RM} \frac{\sin \theta_{1}}{\sin \phi} .
\end{aligned}
$$

Where

$$
\begin{aligned}
& \theta_{1}=\cos ^{-1}\left(\frac{\mathbf{R M} \cdot \boldsymbol{C h} \boldsymbol{R M}}{\mathrm{RM}}\right) \\
& \theta_{2}=\cos ^{-1}\left(\frac{\mathbf{R M} \cdot \mathbf{F}_{\text {lab }}}{\mathrm{RM}}\right) \\
& \phi=180-\left(\theta_{1}+\theta_{2}\right) .
\end{aligned}
$$

Where, as before, normal type indicates a scalar (magnitude), bold type indicates a vector and italics the directional unit vector. The sum of the two angles $\left(\theta_{1}+\theta_{2}\right)$ should equal $90^{\circ}$, if not then this indicates that the $\mathrm{RM}$ is not in the defined ChRM F $F_{\text {lab }}$ plane. This will happen if the ChRM is not stable, the sample is anisotropic, there is an error in the direction of $\mathrm{F}_{\mathrm{lab}}$, or the magnetometer is not measuring correctly. The first two are the most likely scenarios however whatever the cause, if $\theta_{1}+\theta_{2} \neq 90^{\circ}$ then the palaeointensity estimate cannot be accepted. This so-called 'theta check' is always carried out and provides a useful quality control. However, it only detects non-ideal behaviour that occurs outside the defined ChRM Flab plane. If the nonideal behaviour is within the defined ChRM Flab plane then other criteria such as linearity of the NRM $\mathrm{T}_{\mathrm{M}} \mathrm{RM}$ plot and demagnetisation behaviour must be used to judge the success of using the perpendicular applied field method. Some simple scenarios have been taken and synthetic data generated in Fig. 2 to demonstrate the effect of starting the experiment before removal of a secondary component (case 2 

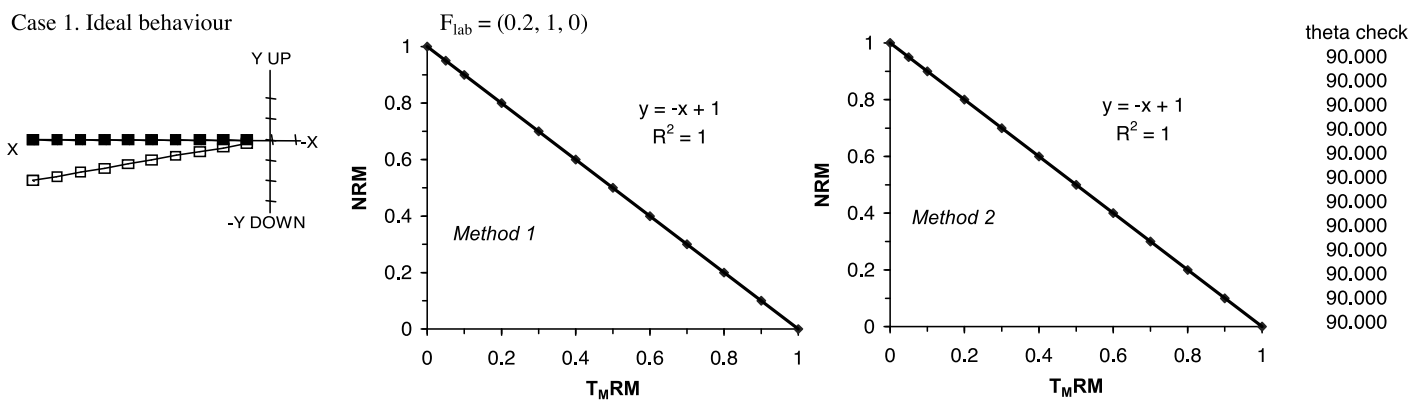

Case 2. ChRM not stable (secondary cmpt not in ChRM $F_{\text {lab }}$ plane) $\quad F_{\text {lab }}=(0,1,0)$
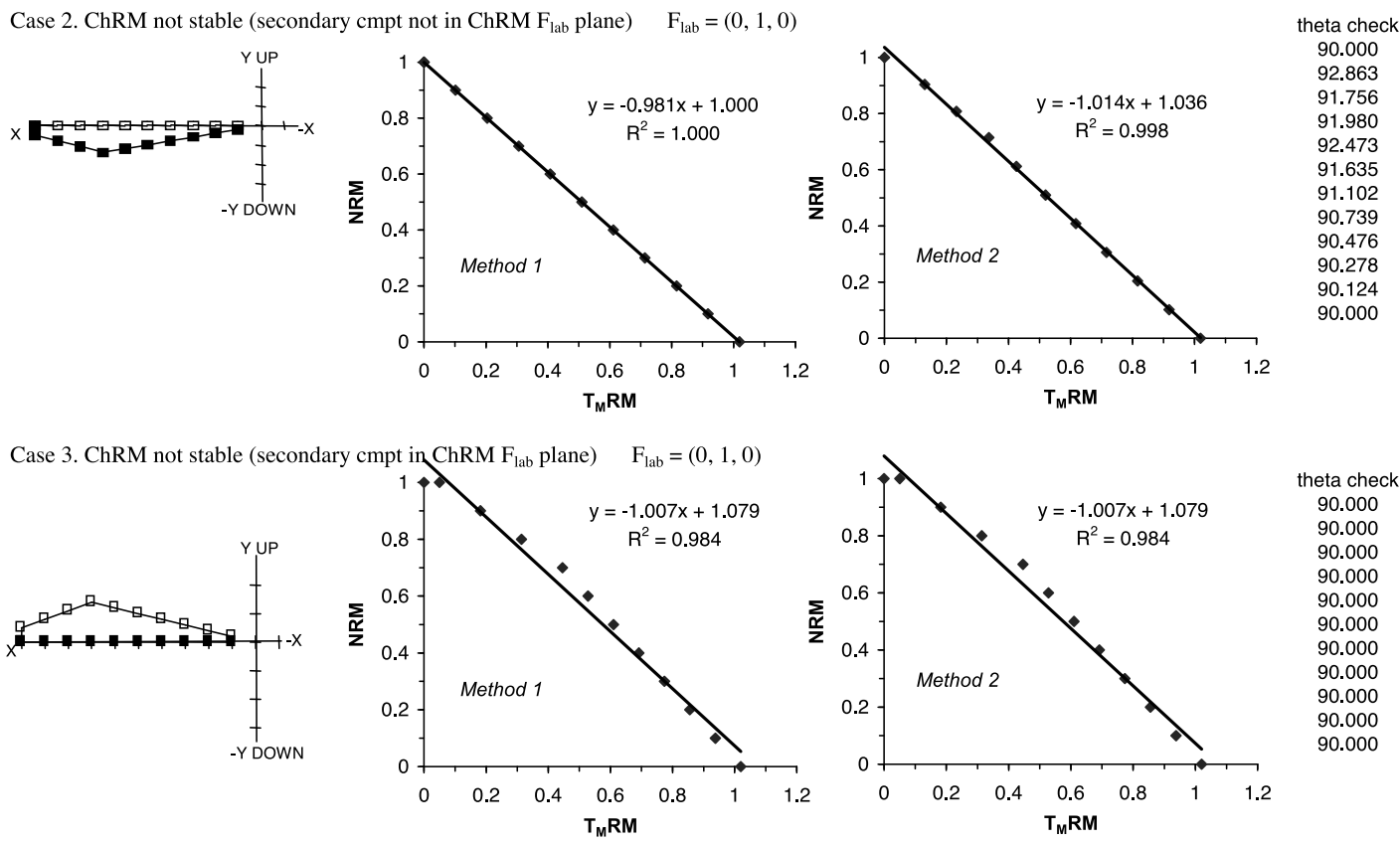

Case 4. Anisotropic Sample
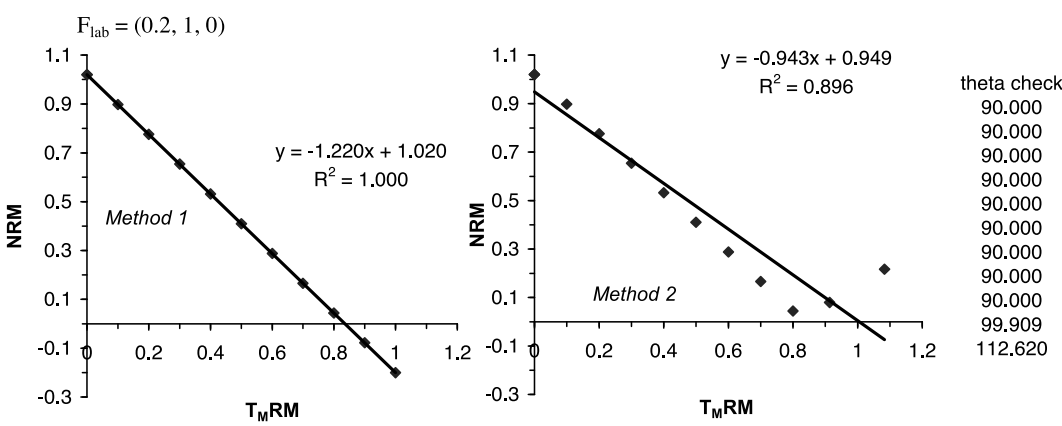

Fig. 2. Synthetically generated data to illustrate the effect of starting the experiment before removing a secondary component of remanence and sample anisotropy when using the perpendicular applied field method. The left hand plot is an orthogonal vector plot OVP with solid (open) symbols representing the vertical (horizontal) projections of the NRM vector. The direction of $F_{\text {lab }}$ is given for each case. In all cases total NRM intensity $=$ total $\mathrm{T}_{\mathrm{M}} \mathrm{RM}$ intensity so that in the ideal Case 1 the NRM $\mathrm{T}_{\mathrm{M}} \mathrm{RM}$ plot has a gradient of -1 . Method 1 and Method 2 and theta check are defined in the text. In Cases 2 and $320 \%$ of the initial remanence is composed of a secondary component of remanence that is completely removed by the fifth data point (power step). In Case 2 the secondary remanence is not in the defined ChRM Flab plane, whereas in Case 3 it is. In Case 4 the $\mathrm{T}_{\mathrm{M}} \mathrm{RM}$ is acquired in a direction within the ChRM $\mathrm{F}_{\text {lab }}$ plane, but $101^{\circ}$ away from the ChRM as opposed to $90^{\circ}\left(11^{\circ}\right.$ between $\mathrm{T}_{\mathrm{M}} \mathrm{RM}$ and the direction of $\left.\mathrm{F}_{\mathrm{lab}}\right)$.

and 3) and anisotropy (case 4) on the NRM T $\mathrm{T}_{\mathrm{M}} \mathrm{RM}$ plot and the theta check. If the palaeointensity experiment is started before any viscous or secondary components are removed erroneous results will occur as shown in Cases 2 and 3 of Fig. 2 illustrating the necessity of carrying out low power demagnetisation prior to commencing the main part of the experiment. Whilst it is not possible to determine the demagnetisation behaviour of the NRM directly during an experiment it is possible to monitor the direction using the data from demagnetisation $\mathrm{pT}_{\mathrm{M}} \mathrm{RM}$ tail check steps (Fig. 3) plus, the demagnetisation data obtained from sister samples also provides useful information. For the case of anisotropic samples, if the $T_{M} R M$ is acquired out of the ChRM $F_{\text {lab }}$ plane then this will be seen in failure of the theta check. If the $T_{M} R M$ is within the ChRM $F_{\text {lab }}$ plane then this will be picked up in the NRM $\mathrm{T}_{\mathrm{M}} \mathrm{RM}$ plots. In Case 4 of Fig. 2 the $\mathrm{T}_{\mathrm{M}} \mathrm{RM}$ is acquired at an angle greater than $90^{\circ}$ away from the ChRM. This results in negative NRM values when 

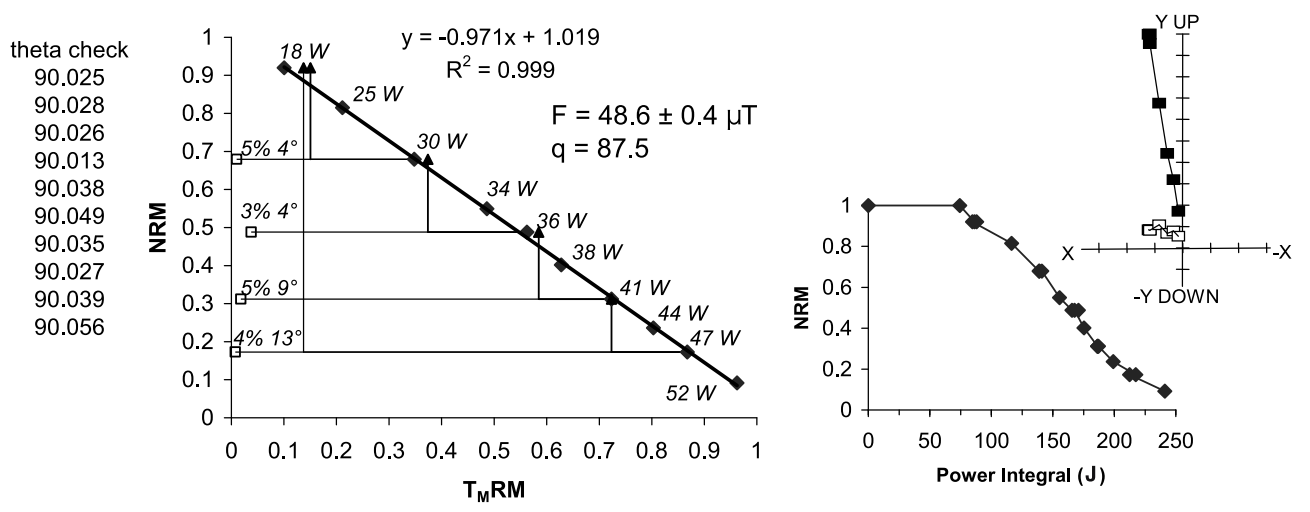

Fig. 3. Example of a microwave perpendicular applied field experiment for a sample containing a laboratory induced TRM (produced in a field of 50 $\mu \mathrm{T}$ ). NRM $\mathrm{T}_{\mathrm{M}} \mathrm{RM}$ plot with $\mathrm{pT}_{\mathrm{M}} \mathrm{RM}$ (triangles and thin solid lines) and $\mathrm{pT}_{\mathrm{M}} \mathrm{RM}$ tail checks (open squares and dashed lines). Microwave powers used are indicated beside the data points. The percentage of $\mathrm{pT}_{\mathrm{M}} \mathrm{RM}$ tail in the direction $\mathrm{F}_{\text {lab }}$ and the angle between the tail check and the NRM direction are indicated above the tail check. $\mathrm{F}$ is the determined palaeointensity and $\mathrm{q}$ is the quality parameter of Coe et al. (1978). The OVP is from the tail checks.

using Method 1 and an apparent increase in $\mathrm{T}_{\mathrm{M}} \mathrm{RM}$ and associated failure of the theta check with Method 2 once RM is at an angle greater than $90^{\circ}$ away from the ChRM. Conversely if the $T_{M} R M$ is acquired at an angle less than $90^{\circ}$ away from the ChRM then the NRM will never reach zero (for both methods).

Using a combination of the theta check, NRM demagnetisation behaviour and linearity of the NRM $\mathrm{T}_{\mathrm{M}} \mathrm{RM}$ plot it is possible to determine if the ChRM is stable or the sample behaves anisotropically. As in conventional methods $\mathrm{pT}_{\mathrm{M}} \mathrm{RM}$ and $\mathrm{pT}_{\mathrm{M}} \mathrm{RM}$ tail checks (and non linearity of the NRM $\mathrm{T}_{\mathrm{M}} \mathrm{RM}$ plot) indicate multi-domain behaviour and alteration during the experiment. Combining all these checks the microwave perpendicular applied field method can therefore be used to produce high quality palaeointensity results, as is illustrated in Fig. 3, for a basalt sample containing a laboratory induced remanence.

The preferred strategy with microwave palaeointensity analysis is to carry out both double 'heating' and perpendicular applied field methods for any suite of samples (e.g. Hill et al., 2002b, 2005, 2006; Gratton et al., 2005a). Both methods have advantages and disadvantages and consistency within the methods provides added confidence in the palaeointensity results. It must be remembered though that with any palaeointensity method or procedure the basic assumption that the NRM is a TRM must hold true for the palaeointensity result to be meaningful.

\section{Conclusions}

In the quest to obtain information regarding the past strength of the geomagnetic field many different experimental methods have been suggested. Most methods are variants of the Thellier method with the key motivation behind the single heating perpendicular applied field variant first suggested by Kono being to reduce experimental time and the motivation for the microwave palaeointensity technique being to reduce alteration of the magnetic minerals during the experiment. Whilst the original Kono perpendicular applied field method has not been routinely used due in large part to technical difficulties it was ideally suited for microwave palaeointensity methods when the reproducibility of absorbed power was problematic. With the advances in the microwave systems, reproducibility of absorbed power has improved and it is now possible to carry out any variant of the Thellier method. The perpendicular applied field method is however still used routinely as it is quick and easy to use, avoids any potential power reproducibility issues and provides a comparison with results obtained through other methods.

Acknowledgments. John Share, Derek Walton, Martin Gratton and everyone else who has worked on the microwave systems. NERC, Leverhulme and the University of Liverpool are thanked for funding microwave research and equipment (NE/B50572X/1) over the years. MJH acknowledges NERC grant NE/C51982X/1 which funds her current position. Henry Halls and Pierre Camps are thanked for their helpful reviews.

\section{References}

Biggin, A. J., First-order symmetry of weak-field partial thermoremanence in multi-domain (MD) ferromagnetic grains: 2. Implications for Thellier-type palaeointensity determination, Earth Planet. Sci. Lett., 245, 454-470, 2006

Böhnel, H., A. J. Biggin, D. Walton, J. Shaw, and J. A. Share, Microwave palaeointensities from a recent Mexican lava flow, baked sediments and reheated pottery, Earth Planet. Sci. Lett., 214, 221-236, 2003.

Casas, L1., J. Shaw, M. Gich, and J. A. Share, High-quality microwave archaeointensity determinations from an early 18th century ad English brick kiln, Geophys. J. Int., 161, 653-661, 2005.

Coe, R. S., The determination of palaeointensities of the Earth's magnetic field with emphasis on mechanisms which would cause non ideal behaviour in the Thelliers method, J. Geomag. Geoelectr., 19, 157-179, 1967.

Coe, R. S., C. S. Grommé, and E. A. Mankinen, Geomagnetic paleointensities from radiocarbon-dated lava flows on Hawaii and the question of the Pacific nondipole low, J. Geophys. Res., 83, 1740-1756, 1978.

Downey, W. S. and D. H. Tarling, Archaeomagnetic dating of Santorini volcanic eruptions and fired destruction levels of late Minoan civilization, Nature, 309, 519-523, 1984.

Gratton, M. N., A. Goguitchaichvili, G. Conte, J. Shaw, and UrrutiaFucugauchi, Microwave palaeointensity study of the Jorullo volcano (Central Mexico), Geophys. J. Int., doi:10.1111/j.1365-246X.2005. 02619.x, 2005a.

Gratton, M. N., J. Shaw, and E. Herrero-Bervera, An absolute palaeointensity record from SOH1 lava core, Hawaii using the microwave technique, Phys. Earth Planet. Int., 148, 193-214, 2005 b.

Halls, H. C., N. J. McArdle, M. Gratton, M. J. Hill, and J. Shaw, Microwave paleointensities from dyke chilled margins: a way to obtain long term variations in geodynamo intensity for the last three billion years, Phys. Earth Planet. Int., 131, 237-249, 2004. 
Hill, M. J. and J. Shaw, Palaeointensity results for historic lavas from Mt. Etna using microwave demagnetization/remagnetization in a modified Thellier type experiment, Geophys. J. Int., 139, 583-590, 1999.

Hill, M. J. and J. Shaw, Magnetic field intensity study of the 1960 Kilauea lava flow, Hawaii, using the microwave palaeointensity technique, Geophys. J. Int., 142, 487-504, 2000.

Hill, M. J., M. N. Gratton, and J. Shaw, A comparison of thermal and microwave palaeomagnetic techniques using lava containing laboratory induced remanence, Geophys. J. Int., 151, 157-163, 2002a.

Hill, M. J., M. N. Gratton, and J. Shaw, Palaeomagnetic investigation of Tertiary lava from Barrington Tops, NSW, Australia, using thermal and microwave techniques, Earth Planet. Sci. Lett., 198, 245-256, 2002 b.

Hill, M. J., J. Shaw, and E. Herrero-Bervera, Palaeointensity record through the Lower Mammoth Reversal from the Waianae volcano, Hawaii, Earth Planet. Sci. Lett., 230, 255-272, 2005.

Hill, M. J., J. Shaw, and E. Herrero-Bervera, Determining palaeointensity from the Gilbert Gauss Reversal recorded in the Pu'u Heleakala lava section, Wai'anae Volcano, Oahu, Hawaii, Earth Planet. Sci. Lett., 245, 29-38, 2006.

Kono, M., Intensities of the Earth's magnetic field about 60 m.y. agon determined from the Deccan trap basalts, India, J. Geophys. Res., 79, 1135-1141, 1974.

Kono, M., Palaeomagnetism and palaeointensity studies of Scottish Devonian volcanic rocks, Geophys. J. R. astr. Soc., 56, 385-396, 1979.

Kono, M. and H. Tanaka, Analysis of the Thelliers' method of paleointensity determination 1: Estimation of statistical errors, J. Geomag. Geoelctr., 36, 267-284, 1984.

Kono, M. and N. Ueno, Paleointensity determination by a modified Thellier method, Phys. Earth Planet. Int., 13, 305-314, 1977.

Nagata, T., The natural remanent magnetisation of volcanic rocks and its relation to geomagnetic phenomena, Bull. Earthq. Res. Inst., 21, 1-196,
1943.

Riisager, P. and J. Riisager, Detecting multidomain magnetic grains in Thellier palaeointensity experiments, Phys. Earth Planet. Int., 125, 111-117, 2001.

Rogers, J., J. W. M. Fox, and M. J. Aitken, Magnetic anisotropy in ancient pottery, Nature, 277, 644-646, 1979.

Shaw, J., D. Walton, S. Yang, T. C. Rolph, and J. A. Share, Microwave archaeointensities from Peruvian ceramics, Geophys. J. Int., 124, $241-$ 244, 1996.

Thellier, E. and O. Thellier, Sur l'intensité du champ magnétique terrestre dans le passé historique et géologique, Annales de Géophysique, 15, 285-376, 1959.

Thomas, N., M. J. Hill, and A. Garcia, Comparison of the CoeThellier-Thellier And Microwave Palaeointensity Techniques using high-Titanium titanomagnetites: Results from a Tertiary Basaltic Intrusion from the Sydney Basin, New South Wales, Earth Planet. Sci. Lett., 229, 15-29, 2004.

Valet, J. P., Time variations in geomagnetic intensity, Reviews Geophys., 41, 1/1004, 2003.

Walton, D., J. A. Share, T. C. Rolph, and J. Shaw, Microwave magnetisation, Geophys. Res. Lett., 20, 109-111. 1993.

Walton, D., S. Snape, T. C. Rolph, J. Shaw, and J. Share, Application of ferrimagnetic resonance heating to palaeointensity determinations, Phys. Earth Planet. Int., 94, 183-186, 1996.

$\mathrm{Xu}, \mathrm{S}$. and D. J. Dunlop, Thellier palaeointensity theory and experiments for multidomain grains, J. Geophys. Res., 109, B07103, doi:10.1029/ 2004JB003024, 2004.

M. J. Hill (e-mail: M.Hill@liverpool.ac.uk) and J. Shaw 